\title{
Política de indexação: um estudo nas Bibliotecas Públicas do Estado do Rio de Janeiro
}

\author{
Indexing policy: a study in the Public Libraries of the State of Rio de Janeiro
}

\author{
Mariana Acorse Lins de Andrade \\ Especialista em Informação Científica e Tecnológica em Saúde - FIOCRUZ \\ E-mail: mariacorse@hotmail.com
}

\begin{abstract}
Deise Maria Antonio Sabbag
Doutora em Ciência da Informação pela Universidade Estadual Paulista Júlio de Mesquita Filho - UNESP,
campus de Marília.

Professora do curso de Biblioteconomia e Ciências da Informação e da Documentação - FFCLRP/USP.

E-mail: deisemarian@gmail.com
\end{abstract}

\section{Resumo}

O trabalho apresenta e define as Bibliotecas Públicas do Estado do Rio de Janeiro e as Bibliotecas Parque. Define a Indexação e apresenta seu histórico. Descreve a Política de Indexação e mostra sua importância. Identifica e analisa os fatores existentes para o planejamento dentro do sistema de informação, com base nos autores Carneiro (1985), Foskett (1973) e Rubi (2004). Identifica e analisa os elementos que devem ser considerados ao se elaborar uma Política de Indexação, com base nos autores Carneiro (1985), Foskett (1973) e Rubi (2004). Investiga a Política de Indexação nas Bibliotecas Públicas do Estado do Rio de Janeiro.

Palavras-chave: Política de indexação. Indexação. Biblioteca Pública. Rio de Janeiro.

\begin{abstract}
This research presents and defines the Public Libraries in Rio de Janeiro State as well as the Park Libraries. It also defines indexing and presents its history. Describes the Indexing Policy and presents its relevance. Identifies and analyses existing factors regarding planning within the information system, based upon authors such as Carneiro (1985), Foskett (1973), and Rubi (2004). Also identifies and analyses elements that should be considered when creating an Indexing Policy, based upon the following authors: Carneiro (1985), Foskett (1973)and Rubi (2004). Investigates the Indexing Policies in the Public Libraries in Rio de Janeiro State.
\end{abstract}

Key-words: Indexing policy. Indexing. Public Library. Rio de Janeiro. 


\section{Introdução}

Consideramos a importância e a necessidade da construção de formas de representação da informação, explícita e registrada, possibilitando sua recuperação, seu reuso, sua revisitação. Por meio da criação de metodologias, a Biblioteconomia e Ciência da Informação estabelecem parâmetros de ordem contribuindo para a geração, transferência, utilização e preservação de documentos nos mais diversos ambientes informacionais

Novos paradigmas de espaço-tempo interferem neste cenário, onde a globalização, as novas práticas dos produtos e serviços eletrônicos, a administração do conhecimento e da informação, a diversidade e a ética, e responsabilidade social, fazem com que a gestão dos ambientes informacionais e suas técnicas profissionais sejam repensadas em uma nova lógica, por meio de novos parâmetros e novas orientações que tenham como diferencial o melhor uso dos recursos disponíveis, bem como a inserção e criação de outros.

Um dos grandes desafios dos ambientes informacionais e de seus profissionais na contemporaneidade é a constante busca de capacitação para a incorporação de novos modelos, métodos, técnicas, instrumentos e atitudes, diante das mudanças e inovações que ocorrem para a apropriação do conhecimento e desenvolvimento de competências de recuperação da informação.

A criação de políticas organizacionais que visam o oferecimento e a criação de competências para o uso dos bens que estão à disposição contribui para diminuir os espaços de distanciamento daqueles que possuem competência dos que não a possuem, dos que dominam as inovações oriundas da tecnologia dos que não dominam.

No âmbito das bibliotecas a política é um elemento de gestão indispensável sendo um instrumento utilizado para o planejamento sendo que as políticas de tratamento da informação são fundamentais, pois integram os elementos necessários para a projeção da estrutura das organizações. Mudanças no estabelecimento das políticas podem influenciar atitudes e comportamentos dos bibliotecários atuantes nas bibliotecas.

Assim como nas esferas empresariais, o contexto administrativo das bibliotecas deve levar em consideração seis elementos básicos para sua estrutura organizacional: a) a

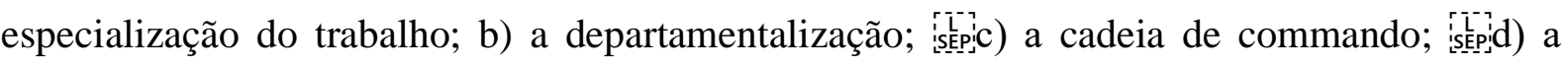

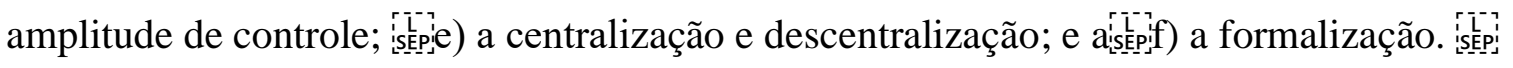


Trataremos neste artigo especificamente do elemento formalização considerando que este contempla as atividades padronizadas do processo de análise e síntese dos documentos. Neste sentido, o objetivo desta pesquisa foi verificar a existência de uma política de indexação nas bibliotecas públicas do Estado do Rio de Janeiro buscando investigar as regras que orientam os procedimentos dos profissionais que atuam dentro dessas bibliotecas. Atividades de alta formalização, como a indexação, necessitam de políticas que representem parâmetros, que vão contribuir efetivamente para a tomada de decisão nas bibliotecas e nos sistemas de recuperação da informação.

\section{Biblioteca Pública}

As bibliotecas públicas surgiram com a missão de atender às necessidades de informação, educação e cultura da todas as pessoas, independente de classe social, cor, religião, idade, sexo ou profisssão. Elas devem ser mantidas pelo governo, devem ser de fácil acesso à população e não devem cobrar pelos serviços prestados aos seus usuários.

Suaiden (1995, p. 20) afirma que a biblioteca pública tem por objetivo primordial preservar e difundir o conhecimento, principalmente no que se refere à cultura local, e dentre todos os tipos de bibliotecas é a única que possui realmente características de uma instituição social, tanto pela amplitude de seu campo de ação como pela diversificação de seus usuários.

Cunha e Cavalcanti (2008, p. 52) definem a biblioteca pública como "a que é posta à disposição da coletividade de uma região, município ou estado, e que é financiada principalmente por dotações governamentais". E o Manifesto da UNESCO (IFLA, 1994), define a biblioteca pública como o centro local de informação, tornando prontamente acessíveis aos seus utilizadores o conhecimento e a informação de todos os gêneros.

O Manifesto da UNESCO (IFLA, 1994) sustenta que os serviços da biblioteca pública devem ser oferecidos com base na igualdade de acesso para todos, sem distinção de idade, raça, sexo, religião, nacionalidade, língua ou condição social. Os serviços e materiais específicos devem ser postos à disposição dos usuários que, por qualquer razão, não possam usar os serviços e os materiais correntes, como, por exemplo, minorias linguísticas, pessoas deficientes, hospitalizadas ou reclusas. Todos os grupos de todas as idades devem encontrar documentos adequados às suas necessidades. As coleções e serviços devem incluir todos os tipos de suporte e tecnologias modernas, apropriados assim como fundos tradicionais, e é essencial que sejam 
de elevada qualidade e adequadas às necessidades e condições locais. As coleções devem refletir as tendências atuais e a evolução da sociedade, bem como a memória da humanidade e o produto da sua imaginação. As coleções e os serviços devem ser isentos de qualquer forma de censura ideológica, política ou religiosa e de pressões comerciais.

A Fundação Biblioteca Nacional (2000) e o Manifesto da UNESCO (IFLA, 1994) corroboram sobre o conceito de biblioteca basear-se na igualdade de acesso para todos, sem restrição de idade, raça, sexo, status, social, etc. e na disponibilização à comunidade de todo tipo de conhecimento. Também concordam que esta biblioteca deve oferecer todos os gêneros de obras que sejam do interesse da comunidade a que pertence, bem como a literatura em geral, além de informações básicas sobre a organização do governo, serviços públicos em geral e publicações oficiais.

De acordo com Fundação Biblioteca Nacional (2000), a Biblioteca Pública é um elo entre a necessidade de informação de um membro da comunidade e o recurso informacional que nela se encontra organizado e à sua disposição. Além disso, afirma que uma biblioteca pública deve constituir-se em um ambiente realmente público, de convivência agradável, onde as pessoas possam se encontrar para conversar, trocar idéias, discutir problemas, auto-instruirse e participar de atividades culturais e de lazer.

Toda biblioteca pública deve estar registrada no Sistema de Bibliotecas Públicas (SNBP), criado na Fundação Biblioteca Nacional (FBN) pelo Decreto Presidencial n. 520 de 13 de maio de 1992, que tem como objetivo principal o fortalecimento das bibliotecas públicas no país (FUNDAÇÃO BIBLIOTECA NACIONAL, 2000). O SNBP tem com segmentos a coordenadoria nacional, os sistemas estaduais e as bibliotecas públicas estaduais e municipais. Os Sistemas Estaduais funcionam em cada estado da federação, chefiado, geralmente, pelas bibliotecas públicas estaduais, que passam, por sua vez, a articular-se com as bibliotecas públicas municipais. Uma vez cadastrada no Sistema, a biblioteca passará a usufruir dos programas desenvolvidos pelo Sistema Nacional de Bibliotecas Públicas, em campo nacional e estadual (FUNDAÇÃO BIBLIOTECA NACIONAL, 2000). A partir do ano de 2014 o SNPB sofreu uma mudança na sua organicidade alterando sua configuração e subordinação sendo transferido para Brasília e incorporado à Secretaria Executiva do Ministério da Cultura (MinC).

No âmbito das bibliotecas públicas temos as denominadas Bibliotecas Parque. Bibliotecas Parque são bibliotecas públicas multifuncionais em áreas de risco, com acesso imediato e fácil à informação. Ao encararem a transformação do conceito de leitura, apresentam 
espaços dinâmicos que visam a construção de uma sociedade mais igualitária, aberta a todo tipo de conhecimento (RIO DE JANEIRO, 2017).

De acordo com Flusser (1980, p. 132), o público potencial pode vir a ser público efetivo, o não-público jamais o será. O público potencial pode se tornar público efetivo com uma maior difusão, uma redução de preços, uma descentralização cultural ou, por exemplo, uma política de democratização cultural. O não público não será transformado, ele continuará a ser marginalizado e esquecido. Para que uma biblioteca pública seja plenamente pública é necessário que ela se volte para o não-público. Jeanson (1973, p. 30 apud Flusser 1980, p. 132) “o que nós reivindicamos é que o não público possa romper com o seu isolamento atual, sair do gueto situando-se de maneira cada vez mais consciente no contexto social e histórico, liberandose sempre mais das mistificações que tendem a fazê-lo cúmplice das situações reais que lhe são infligidas”. Para Flusser (1980, p. 133), a biblioteca verdadeiramente pública é a transformação estrutural da biblioteca tal como existente hoje, em uma que participe do processo de dar a palavra ao não público. E esta é exatamente a proposta das Bibliotecas Parque.

As Bibliotecas Parque, vinculadas ao Programa de Aceleração do Crescimento (PAC), oferecem espaços como ludoteca, filmoteca, sala de leitura para portadores de deficiências visuais, cineteatro, cafeteria, músicas digitalizadas, acesso à internet, acesso às estantes, empréstimo domiciliar e atividades para crianças e jovens. E, assim, criam um ambiente de convivência e convergência na comunidade, contribuindo para a diminuição da violência e para a inclusão social (RIO DE JANEIRO, 2017).

A Biblioteca Pública do Estado do Rio de Janeiro (BPE) é o núcleo do Sistema Estadual de Bibliotecas, responsável pela implantação de uma política de bibliotecas públicas nos municípios do Estado do Rio de Janeiro. A BPE atende às bibliotecas públicas municipais, bibliotecas de unidades escolares das redes estadual e municipal, bibliotecas comunitárias do Estado e às instituições privadas que solicitam apoio. Também proporciona assessoria técnica e capacitação profissional para implantação e modernização dos serviços das bibliotecas atendidas (RIO DE JANEIRO, 2017).

A Biblioteca Pública de Niterói passou por uma obra de restauração, e foi transformada num espaço pautado pelo livre acesso de informação, num modelo similar ao da Biblioteca Parque de Manguinhos, sua prima-irmã - ambas vinculadas à Secretaria de Estado de Cultura (RIO DE JANEIRO, 2017). 
Política de indexação: um estudo nas Bibliotecas Públicas do Estado do Rio de Janeiro

A Biblioteca Parque de Manguinhos é a primeira de uma rede que a Secretaria de Estado de Cultura do Rio de Janeiro vem implementando, com o objetivo de estruturar um novo patamar de atendimento às comunidades do estado. A Biblioteca Parque da Rocinha foi inaugurada em junho de 2012, tendo como principais referências as bem-sucedidas experiências implementadas em Medelin e Bogotá, na Colômbia, bem como a Biblioteca Parque de Manguinhos.

As Bibliotecas Parque de Manguinhos e da Rocinha e as Bibliotecas Públicas do Estado do Rio de Janeiro e de Niterói são um espaço cultural e de convivência, com qualidade física, humana e de serviços. Essas bibliotecas objetivam ser lugares que se aproximem de centros culturais com ampla acessibilidade, realizando atividades culturais e de promoção de leitura nos mais diversos suportes, visando estimular a produção, a fruição e a difusão das produções artísticas e, especialmente, a viabilização do acesso à cultura.

\section{Indexação}

A indexação é uma das atividades que compõem a análise documentária. Esta pode ser definida como um "conjunto de procedimentos utilizados para exprimir o conteúdo dos documentos científicos sob forma destinada a facilitar a sua localização ou consulta" (GARDIN apud KOBASHI, 1994, p. 15). Para Kobashi (1994) o tratamento documentário é dividido em dois aspectos: a representação descritiva e a análise documentária. Temos como produto da representação descritiva as referências bibliográficas, e como produto da análise documentária o resumo, representando o documento original em forma textual condensada, e o índice, representando o texto por meio de uma Linguagem Documentária.

De acordo com o Glossário de Análise Documentária (2004, p. 9-10) a análise documentária pode ser definida como: “operação que consiste em representar o conteúdo de um documento de forma condensada" (ACCART; RÉTHY, 1990 apud MENEZES; CUNHA; HEEMANN, 2004, p. 9); e "atividade orientada para a identificação e descrição do conteúdo dos documentos, de forma distinta do original, com o propósito de facilitar seu armazenamento, difusão e recuperação da informação em conformidade com as necessidades dos usuários" (ÂNGULO MARCIAL, 1996 apud MENEZES; CUNHA; HEEMANN, 2004, p. 9).

Para Chaumier (1988) a indexação é a parte mais importante da análise documentária, pois condiciona o valor de um sistema documentário. UNISIST apud Chaumier (1988) define 
a indexação como a "operação que consiste em escrever e caracterizar um documento, com o auxílio da representação dos conceitos nela contidos”.

Podemos entender a indexação como uma atividade que implica na atribuição de termos a um documento (palavras-chave, descritores, cabeçalho de assunto, etc) a fim de representar os assuntos por ele tratados, através de elementos de uma linguagem natural ou documentária (ASSOCIAÇÃO BRASILEIRA DE NORMAS TÉCNICAS, 1992; CINTRA, 1983; CUNHA; CAVALCANTI, 2008).

$\mathrm{Na}$ atividade de indexação o profissional identifica o tema do documento que, de acordo com Vickery (1980, p. 30), é a característica mais importante da organização dos documentos, pois determina a natureza do que trata o documento.

De acordo com Chaumier (1988, p. 63), uma indexação inadequada ou uma indexação insuficiente representam $90 \%$ das causas essenciais para a aparição de "ruídos" ou de "silêncios" em uma pesquisa. Os $10 \%$ restantes serão devidos a causas mecânicas tais como: erro de perfuração, de codificação, de transcrição, etc. Os ruídos são documentos não pertinentes à questão, que são extraídos do fichário por ocasião de uma pesquisa bibliográfica. Já os documentos pertinentes existentes no acervo, não recuperados durante a pesquisa, produzem o que se denomina silêncio, ou seja, ausência de resposta (CHAUMIER, 1988, p. $63)$.

De acordo com Lancaster (2004, p. 27), os fatores que influenciam no desempenho de um sistema de recuperação da informação são: a Política de Indexação e a exatidão da indexação.

\section{Política de Indexação}

Quando uma tarefa é altamente padronizada, seus executores possuem baixa autonomia no seu processo decisório, não decidem sobre o que, quando e como deve realizado, isso é desejável para que os profissionais trabalhem o mesmo insumo sempre a mesma forma, produzindo os mesmos resultados de forma consistente e uniforme (ROBBINS, 2008). Evidentemente, o grau de formalização pode variar de acordo com função do profissional e a atividade que ele realiza sendo consideradas estas como funções de baixa formalização.

As bibliotecas compõem atividades de baixa formalização e alta formalização. Dentre 
as atividades que necessitam alta formalização encontram-se as relacionadas à análise documental que possui os conceitos fundamentais de análise e documento. Na análise "tem-se a distribuição ou separação de um todo em suas partes componentes de modo a melhor conhecer seus elementos característicos" (GUIMARÃES, 2003, p. 101). Esta análise, pode assumir uma dimensão de forma, relativa ao processo de descrição bibliográfica, chamada de catalogação, onde os aspectos extrínsecos do documento são extraídos possibilitando sua identificação e localização; e, a dimensão de conteúdo, por meio de linguagens documentárias são realizados os processos de condensação e de representação dos documentos, analisam e descrevem os aspectos intrínsecos ligados ao conteúdo temático.

Dessa forma, podemos considerar a indexação como uma atividade de alta formalização que necessita do estabelecimento de políticas que pautem os procedimentos dos profissionais que atuam dentro das unidades de informação, pois estas representam parâmetros ou orientações que contribuem efetivamente para a tomada de decisão nas unidades e sistemas de recuperação da informação. Políticas são "parâmetros ou orientações que facilitam a tomada de decisão pelo executivo" dentro das unidades de informação (OLIVEIRA, 2006). Refletem e interpretam os objetivos e desafios da gestão buscando reduzir incertezas e minimizando os erros. Ela não é apenas uma formalidade para os profissionais, mas um guia útil que demonstra a direção.

A Política é um plano contínuo de diretrizes gerais para a tomada de decisão. Diretrizes, ou Políticas, "são orientações para a tomada de decisão, [...] reflete um objetivo e orienta os gerentes e funcionários em direção a esses objetivos em situações que requeiram critérios e julgamento" (HAMPTON, 1992, p. 204). As políticas ou diretrizes têm por finalidade orientar o comportamento dos indivíduos e grupos, a longo prazo, especialmente em situações repetitivas ou permanentes. As Políticas são decisões prévias e padronizadas, que delimitam a faixa de ação para o comportamento, dizendo o que se deve fazer em casos particulares (MAXIMIANO, 2000, p. 191).

Transferindo isso para a realidade das bibliotecas e da prática profissional, “encontramos políticas gerais e políticas específicas, relacionadas à suas diversas áreas de atuação: Políticas de Formação e Desenvolvimento de Coleções, Políticas de Conservação de acervo [...]” (ALMEIDA JÚNIOR, 2000, p. 7). Dentro da unidade de informação as Políticas não são criadas como um instrumento que visam burocratizar ou limitar as ações, mas sim como ferramenta para implementar estratégias. 
Ou seja, a política é a diretriz geral para tomada de decisão que estabelecerá fronteiras em torno delas, dizendo aos bibliotecários quais decisões devem ser tomadas e quais não podem, orientando desse modo, o pensamento dos profissionais da organização para que sejam coerentes com os objetivos organizacionais.

$\mathrm{Na}$ implantação de um serviço de indexação um grande número de variáveis deve ser considerado, pois estas variáveis irão afetar sensivelmente o desempenho do serviço. Definir essas variáveis, estabelecer princípios e critérios que servirão de guia de tomada de decisões para otimização do serviço, racionalização dos processos e consistência das operações nele envolvidas, são objetivos de uma política de indexação (CARNEIRO, 1985, p. 222).

\section{Procedimentos metodológicos}

Utilizamos os métodos descritivo e exploratório. O método descritivo tem por objetivo expor características de determinada população ou fenômeno. E o método exploratório é usado quando não existem elementos ou dados suficientes para o pesquisador, esse tipo de pesquisa não comporta a formulação de hipótese inicial, porém as mesmas poderão surgir ao longo do trabalho (KAHLMEYER-MERTENS et al, 2007, p. 53).

A técnica de pesquisa utilizada foi entrevista dirigida. Figueiredo e Souza (2011, p. 120) definem a entrevista como uma conversa efetuada face a face entre o informante e o entrevistador, cujo objetivo é colher dados fidedignos através de uma conversação dirigida ou livre. É orientada para um determinado propósito, visando sempre buscar as informações significativas para o tema em estudo. A entrevista dirigida possui perguntas previamente definidas, como um roteiro.

Esta pesquisa teve como locus as seguintes bibliotecas: Biblioteca Pública do Estado do Rio de Janeiro, Biblioteca Pública de Niterói, Biblioteca Parque de Manguinhos e Biblioteca Parque da Rocinha.

Para a identificação e análise dos elementos e fatores para o estabelecimento da política de indexação foram utilizados os requisitos propostos por Carneiro (1985).

\section{Para os fatores:}


Política de indexação: um estudo nas Bibliotecas Públicas do Estado do Rio de Janeiro

a) Identificação da organização à qual está vinculado o sistema de indexação; Identificação da clientela a que se destina o sistema; Mapeamento dos recursos humanos, materiais e financeiros.

\section{Para os elementos:}

a) Cobertura de assuntos; Seleção e aquisição dos documentos-fonte; Processo de indexação: nível de exaustividade, nível de especificidade, escolha da linguagem e capacidade de revocação do sistema; Estratégica de busca; Tempo de resposta do sistema; Forma de saída; Avaliação do sistema.

Características apresentada por Foskett (1973) que são pertinentes para a Política de Indexação: Capacidade de consulta a esmo (browsing); Garantia literária; Formação do indexador. Características apresentadas por Rubi (2004): consulta ao indexador.

\section{Discussão dos resultados}

A primeira etapa da pesquisa foi o levantamento bibliográfico nos periódicos de Ciência da Informação e nas bases de teses e dissertações de programas de pós-graduação, onde pudemos constatar baixa quantidade de materiais publicados sobre Política de Indexação.

A segunda etapa da pesquisa constou da elaboração da entrevista. Na entrevista dirigida, as perguntas podem ser fechadas ou semi-abertas. As perguntas fechadas são utilizadas para obter informações simples e precisas. E as perguntas semi-abertas, quando o propósito do pesquisador é obter informações com certo nível de profundidade. Foram utilizadas as duas formas de perguntas (FIGUEIREDO; SOUZA, 2011, p. 120).

Foram entrevistados a diretora da BPERJ e autora da Política de Indexação e um bibliotecário indexador de cada uma das seguintes bibliotecas: Biblioteca Pública de Niteroi, Biblioteca Parque de Manguinhos e Biblioteca Parque da Rocinha.

Embora a BPERJ estivesse fechada para obras durante a pesquisa, a diretora aceitou participar da entrevista e responder as perguntas. Porém, não pôde responder às questões relacionadas aos usuários, visto que não há atendimento com a biblioteca fechada.

As questões 1, 2 e 3 tiveram o objetivo de identificar a clientela. Questão 1 - Qual a idade em média dos usuários?

- Bibliotecário B: 20 a 30 anos 
- Bibliotecário C: 12 a 18 anos

- Bibliotecário D: 7 a 16 anos

Questão 2 - Qual o grau de escolaridade dos usuários da biblioteca?

Quadro 01 - Escolaridade dos usuários

\begin{tabular}{|l|c|c|c|}
\hline Ensino fundamental incompleto & $\begin{array}{c}\text { Bibliotecário } \\
\text { B }\end{array}$ & $\begin{array}{c}\text { Bibliotecário } \\
\text { C }\end{array}$ & $\begin{array}{c}\text { Bibliotecário } \\
\text { D }\end{array}$ \\
\hline Ensino fundamental completo & & & \\
\hline Ensino médio incompleto & & & \\
\hline Ensino médio completo & & & \\
\hline Ensino superior incompleto & & & \\
\hline Ensino superior completo & & & \\
\hline Pós-graduação & & & \\
\hline Não sei & & & \\
\hline
\end{tabular}

Fonte: Elaboração própria

Questão 3 - Qual é a área mais pesquisada pelos usuários?

Quadro 02 - Área mais pesquisada

\begin{tabular}{|l|l|l|l|}
\hline & $\begin{array}{c}\text { Bibliotecário } \\
\text { B }\end{array}$ & $\begin{array}{c}\text { Bibliotecário } \\
\text { C }\end{array}$ & $\begin{array}{c}\text { Bibliotecário } \\
\text { D }\end{array}$ \\
\hline $\begin{array}{l}\text { Generalidades, Ciência e } \\
\text { Conhecimento }\end{array}$ & & & \\
\hline Filosofia, Psicologia & & & \\
\hline Religião, Teologia & & & \\
\hline Ciências Sociais & & & \\
\hline Matemática, Ciências Naturais & & & \\
\hline $\begin{array}{l}\text { Ciências Aplicadas, Medicina, } \\
\text { Tecnologia }\end{array}$ & & & \\
\hline Artes, Esportes, Arquitetura & & & \\
\hline Linguística, Linguagem, Literatura & & & \\
\hline Biografia, Geografia, História & & & \\
\hline
\end{tabular}

Fonte: Elaboração própria

A questão 4 objetivou verificar teoria e prática sobre a questão do tempo médio de resposta. Questão 4 - Qual o tempo médio utilizado pelo usuário de sua biblioteca para obter as responstas às suas pesquisas, de acordo com a sua observação?

- Bibliotecário B e D: de 1 a 10 minutos.

- Bibliotecário C: mais do que 20 minutos.

A pergunta 5, teve o objetivo de identificar as formas principais de saída dos resultados de buscas da informação, tanto as recomendadas quanto as preferenciais. O sistema das bibliotecas cujos bibliotecários responderam esta questão, informam o resultado da busca em todos os formatos presentes no quadro. O Bibliotecário D, escolheu a opção Nada observado, 
pois seus usuários não consultam o catálogo sozinhos. Questão 5 - De acordo com a sua observação, o usuário de sua biblioteca prefere, como formato de saída dos resultados:

Quadro 03 - Formato de saída

\begin{tabular}{|l|l|l|l|}
\hline & $\begin{array}{c}\text { Bibliotecário } \\
\text { B }\end{array}$ & $\begin{array}{c}\text { Bibliotecário } \\
\text { C }\end{array}$ & $\begin{array}{c}\text { Bibliotecário } \\
\text { D }\end{array}$ \\
\hline $\begin{array}{l}\text { Lista de referências em formato resumido } \\
\text { (autor e título) na tela do terminal }\end{array}$ & & & \\
\hline $\begin{array}{l}\text { Lista de referências em formato resumido } \\
\text { (autor e título) impressas }\end{array}$ & & & \\
\hline $\begin{array}{l}\text { Lista de referências em formato resumido } \\
\text { (autor e título) por e-mail }\end{array}$ & & \\
\hline $\begin{array}{l}\text { Lista de referências em formato completo } \\
\text { (autor, título, localização e sigla da } \\
\text { biblioteca) na tela do terminal }\end{array}$ & & \\
\hline $\begin{array}{l}\text { Lista de referências em formato completo } \\
\text { (autor, título, localização e sigla da } \\
\text { biblioteca) impressas }\end{array}$ & & & \\
\hline $\begin{array}{l}\text { Lista de referências em formato completo } \\
\text { (autor, título, localização e sigla da } \\
\text { biblioteca) por e-mail }\end{array}$ & & & \\
\hline Nada observado & & & \\
\hline
\end{tabular}

Fonte: Elaboração própria

As questões 6, 7 e 8 tiveram o objetivo de identificar a organização. Questão 6 -Como é feita a aquisição dos documentos-fonte?

- Bibliotecário A: compra e doação.

- Bibliotecário B: compra.

- Bibliotecário C: compra.

- Bibliotecário D: compra e doação.

Questão 7 - Que tipo de materiais a biblioteca possui?

Quadro 04 - Tipos de materiais

\begin{tabular}{|l|c|c|c|c|}
\hline & $\begin{array}{c}\text { Bibliotecário } \\
\text { A }\end{array}$ & $\begin{array}{c}\text { Bibliotecário } \\
\text { B }\end{array}$ & $\begin{array}{c}\text { Bibliotecário } \\
\text { C }\end{array}$ & $\begin{array}{c}\text { Bibliotecário } \\
\text { D }\end{array}$ \\
\hline Obras de referência & & & & \\
\hline Periódicos & & & & \\
\hline Filmes & & & & \\
\hline Jogos & & & \\
\hline Livros de ifcção & & & & \\
\hline Livros de literatura & & & & \\
\hline Livros de poesia & & & & \\
\hline Livros infanto- & & & \\
\hline
\end{tabular}




\begin{tabular}{|l|l|l|l|l|}
\hline juvenis & & & & \\
\hline Livros infantis & Músicas, \\
Outros & $\begin{array}{c}\text { Braille, } \\
\text { Audiolivros }\end{array}$ & & \\
\hline
\end{tabular}

Fonte: Elaboração própria

Questão 8 - Qual o gerenciador de informações utilizado (software)? Bibliotecário A, B, C, e D: Alexandria.

Nas questões 9 e 10, objetivou-se conhecer o profissional que realiza a indexação. Questão 9 - O profissional que realiza a indexação é o mesmo que realiza a catalogação?

- Bibliotecário B, C e D: sim.

Questão 10 - Idade e nível de escolaridade do indexador.

- Bibliotecário B: 60 e 29 anos, ambos superior completo.

- Bibliotecário C: 40 anos, especialista.

- Bibliotecário D: 52 anos, especialista.

A questão 11 propõe uma reflexão sobre a necessidade de formação específica do indexador para cada área do conhecimento na qual ele atua. Questão 11 - O indexador em sua biblioteca tem treinamento na(s) área (s) do conhecimento coberta(s) pela biblioteca:

- Bibliotecários C e D: sim.

- Bibliotecário B: não.

A pergunta 12 teve o objetivo de detectar a importância e/ou a existência ou não de programa de educação continuada em recuperação da informação oferecidos aos bibliotecários. Questão12 - Os bibliotecários de seu sistema recebem instrução no uso de outras bases de dados que não a sua?

- Bibliotecários C: sim.

- Bibliotecário B e D: não.

Questão 13 - Marque as alternativas que correspondem a sua área de atuação:

Quadro 05 - Área de atuação

\begin{tabular}{|l|c|c|c|}
\hline & $\begin{array}{c}\text { Bibliotecário } \\
\text { B }\end{array}$ & $\begin{array}{c}\text { Bibliotecário } \\
\text { C }\end{array}$ & $\begin{array}{c}\text { Bibliotecário } \\
\text { D }\end{array}$ \\
\hline $\begin{array}{l}\text { Ciências Exatas e da Terra: Matemática, } \\
\text { Ciência da Computação, Física, Química, } \\
\text { Geociências. }\end{array}$ & & \\
\hline $\begin{array}{l}\text { Ciências Biológicas: Biologia Geral, } \\
\text { Genética, Botânica, Zoologia, Ecologia, }\end{array}$ & & \\
\hline
\end{tabular}


Política de indexação: um estudo nas Bibliotecas Públicas do Estado do Rio de Janeiro

\begin{tabular}{|l|c|c|c|}
\hline & $\begin{array}{c}\text { Bibliotecário } \\
\text { B }\end{array}$ & $\begin{array}{c}\text { Bibliotecário } \\
\text { C }\end{array}$ & $\begin{array}{c}\text { Bibliotecário } \\
\text { D }\end{array}$ \\
\hline Fisiologia, Bioquímica, Farmacologia. & & & \\
\hline Engenharias: Engenharias, Pesquisas & & & \\
Hidráulicas. & & \\
\hline $\begin{array}{l}\text { Ciências da Saúde: Medicina, } \\
\text { Odontologias, Farmácia, Enfermagem, } \\
\text { Educação Física. }\end{array}$ & & \\
\hline Ciências Agrárias: Agronomia, Medicina & & \\
Veterinária, Ciência e Tecnologia de & & \\
Alimentos. & & \\
\hline Ciências Sociais Aplicadas: Direito, & & \\
Administração, Economia, Arquitetura, & & \\
Ciência da Informação, Comunicação. & & \\
\hline Ciências Humanas: Filosofia, Sociologia, & & \\
Psicologia, Educação. & & \\
\hline Linguística, Letras e Artes: Linguística, & & \\
Letras, Artes. & & \\
\hline $\begin{array}{l}\text { Outras: Bibliotecas Centrais, Escolas } \\
\text { Técnicas, Bibliotecas Depositárias, }\end{array}$ & & \\
Centros Referência, etc. & & \\
\hline
\end{tabular}

Fonte: Elaboração própria

O objetivo da questão 14 é averiguar como é tratada a questão da cobertura de assuntos na Política de Indexação dos sistemas de recuperação. Questão 14 - O tratamento dado à cobertura de assuntos indexados em sua biblioteca:

Quadro 06 - Cobertura

\begin{tabular}{|l|l|l|l|l|}
\hline & Bibliotecário A & Bibliotecário B & Bibliotecário C & Bibliotecário D \\
\hline $\begin{array}{l}\text { Abrange a totalidade } \\
\text { dos assuntos dos } \\
\text { itens do acervo }\end{array}$ & & & & \\
\hline $\begin{array}{l}\text { Abrange parte dos } \\
\text { assuntos dos itens do } \\
\text { acervo }\end{array}$ & & & & \\
\hline
\end{tabular}

Fonte: Elaboração própria

As questões 15, 16 e 17 tiveram como objetivo identificar elementos que comprovem a importância de se ter um instrumento de trabalho para nortear a atividade de indexação.

Questão 15 - Existe uma Política de Indexação em sua biblioteca, registrada e aprovada pelos órgãos competentes?

- Bibliotecário A, C e D: sim.

- Bibliotecário B: não. 
Questão 16 - A Política de Indexação de sua biblioteca, se existe, está expressa em:

- Bibliotecário A, B, C e D: um manual de procedimentos pormenorizado para cada procedimento.

Questão 17 - Não estando registrada, qual a importância em se ter esse documento registrado?

- Bibliotecário A, B, C e D: está registrada.

A questão 18 tem o objetivo de estabelecer o grau ideal de exaustividade que a Política de Indexação deve ter. Questão 18 - Quanto à exaustividade, a indexação realizada em sua biblioteca prevê um número de termos:

- Bibliotecário A e B: de 1 a 4.

- Bibliotecário C e D: de 1 a 10.

A pergunta 19 pretende identificar o grau ideal de especificidade que a política de indexação deve ter. Questão 19 - Os termos de indexação usados pela sua biblioteca são preferencialmente:

Quadro 1 - Termos

\begin{tabular}{|l|c|c|c|c|}
\hline & $\begin{array}{c}\text { Bibliotecário } \\
\text { A }\end{array}$ & $\begin{array}{c}\text { Bibliotecário } \\
\text { B }\end{array}$ & $\begin{array}{c}\text { Bibliotecário } \\
\text { C }\end{array}$ & $\begin{array}{c}\text { Bibliotecário } \\
\text { D }\end{array}$ \\
\hline Específicos & & & & \\
\hline Gerais & & & & \\
\hline
\end{tabular}

Fonte: Elaboração própria

O objetivo desta questão 20 é avaliar a questão da padronização, por meio da política de organização do conhecimento, da flexão de gênero dos termos.

Questão 20 - Os termos de indexação usados em sua biblioteca têm flexão de gênero determinada preferencialmente no masculino?

- Bibliotecário A, B e D: sim; Bibliotecário C: não.

A questão 21 tem o objetivo de verificar a questão da padronização, por meio da política de organização do conhecimento, da flexão de número de termos.

Questão 21 - As unidades indexadoras em sua biblioteca estão preferencialmente no singular?

- Bibliotecário A, B, C e D: sim.

As questões 22, 23, 24, 25, 26 e 27 tem o objetivo de identificar teoria e prática sobre 
linguagens documentárias nas políticas de indexação. Questão 22 - Qual a linguagem documentária utilizada em sua biblioteca?

Quadro 08 - Linguagem documentária

\begin{tabular}{|l|c|l|l|l|}
\hline & $\begin{array}{c}\text { Bibliotecário } \\
\text { A }\end{array}$ & Bibliotecário B & $\begin{array}{c}\text { Bibliotecário } \\
\text { C }\end{array}$ & Bibliotecário D \\
\hline Tesauros & & & & \\
\hline $\begin{array}{l}\text { Lista de cabeçalhos } \\
\text { de assunto }\end{array}$ & & & & \\
\hline $\begin{array}{l}\text { Vocabulário } \\
\text { controlado } \\
\text { elaborado pela } \\
\text { biblioteca }\end{array}$ & & & & \\
\hline Linguagem livre & & & & \\
\hline
\end{tabular}

Fonte: Elaboração própria

Questão 23 - A Linguagem Documentária de sua biblioteca, se existe, é em nível:

Quadro 09 - Linguagem Documentária

\begin{tabular}{|l|c|c|c|c|}
\hline & $\begin{array}{c}\text { Bibliotecário } \\
\text { A }\end{array}$ & $\begin{array}{c}\text { Bibliotecário } \\
\text { B }\end{array}$ & $\begin{array}{c}\text { Bibliotecári } \\
\text { o C }\end{array}$ & $\begin{array}{c}\text { Bibliotecário } \\
\text { D }\end{array}$ \\
\hline $\begin{array}{l}\text { Altamente técnico (linguagem } \\
\text { especializada) }\end{array}$ & & & & \\
\hline $\begin{array}{l}\text { Técnico (linguagem } \\
\text { especializada moderada por } \\
\text { mecanismos de aproximação } \\
\text { com a linguagem comum) }\end{array}$ & & & & \\
\hline Não existe & & & & \\
\hline
\end{tabular}

Fonte: Elaboração própria

Questão 24 - A Linguagem Documentária de sua biblioteca é:

Quadro 10 - Linguagem Documentária 2

\begin{tabular}{|l|l|l|l|l|}
\hline & Bibliotecário A & Bibliotecário B & $\begin{array}{c}\text { Bibliotecário } \\
\text { C }\end{array}$ & Bibliotecário D \\
\hline Pré-coordenada & & & & \\
\hline Pós-coordenada & & & & \\
\hline
\end{tabular}

Fonte: Elaboração própria

Questão 25 - São usados qualificadores como parte dos termos de indexação em sua biblioteca?

- Bibliotecário A, C e D: sim; Bibliotecário B: não.

Questão 26 - São usados auxiliares (p. ex. Os geográficos, os de forma, os cronológicos, etc.) na indexação em sua biblioteca? 
- Bibliotecário A, C e D: sim; Bibliotecário B: não.

Questão 27 - A indexação realizada em sua biblioteca prevê o uso de remissivas?

- Bibliotecário A, B, C e D: sim.

As questões 28 e 29 tem o objetivo de mapear os recursos materiais das organizações.

Questão 28 - Quantos computadores são destinados à atividade de indexação?

- Bibliotecário B: 3; Bibliotecário C: 1; Bibliotecário D: 1.

Questão 29 - Quantos computadores são destinados para o acesso ao catálogo?

- Bibliotecário B: 20; Bibliotecário C: 24; Bibliotecário D: 3.

As questões 30 e 31 investigam teoria e prática a respeito dos mecanismos para elaboração de estratégias de busca nos sistemas de recuperação de informação. Questão 30 Marque os mecanismos de estratégia de busca oferecidos pelo seu sistema de recuperação da informação:

Quadro 11 - Estratégia de busca sistema

\begin{tabular}{|c|c|c|c|c|}
\hline & $\begin{array}{c}\text { Bibliotecário } \\
\text { A }\end{array}$ & $\begin{array}{c}\text { Bibliotecário } \\
\text { B }\end{array}$ & $\begin{array}{c}\text { Bibliotecário } \\
\text { C }\end{array}$ & $\begin{array}{c}\text { Bibliotecário } \\
\text { D }\end{array}$ \\
\hline Seleção de catálogos & & & & \\
\hline Busca por bibliotecas & & & & \\
\hline Busca por tipo de material & & & & \\
\hline $\begin{array}{l}\text { Busca por palavras ou frases } \\
\text { em todos os campos }\end{array}$ & & & & \\
\hline $\begin{array}{l}\text { Busca por palavras ou frases } \\
\text { em campos determinados }\end{array}$ & & & & \\
\hline $\begin{array}{l}\text { Busca por autor/ orientador/ } \\
\text { colaborador/responsabilidade }\end{array}$ & & & & \\
\hline Busca por título & & & & \\
\hline Busca por assunto & & & & \\
\hline Busca por editora & & & & \\
\hline Busca por série & & & & \\
\hline Busca por código de barras & & & & \\
\hline Busca por ISSN e/ou ISBN & & & & \\
\hline Busca por número de sistema & & & & \\
\hline Opção de pesquisa simples & & & & \\
\hline Opção de pesquisa avançada & & & & \\
\hline $\begin{array}{l}\text { Opção de pesquisa multi- } \\
\text { campo (cruzamento de mais } \\
\text { de um campo ao mesmo } \\
\text { tempo) }\end{array}$ & & & & \\
\hline Outros. Especifique. & & & & \\
\hline
\end{tabular}

Fonte: Elaboração própria

Questão 31 - De acordo com a sua observação, quais mecanismos de estratégia de busca são mais utilizados pelos usuários de sua biblioteca? 
Política de indexação: um estudo nas Bibliotecas Públicas do Estado do Rio de Janeiro

Quadro 12 - Estratégia de busca usuários

\begin{tabular}{|l|l|l|l|}
\hline & Bibliotecário B & Bibliotecário C & Bibliotecário D \\
\hline Seleção de catálogos & & & \\
\hline Busca por bibliotecas & & & \\
\hline Busca por tipo de material & & & \\
\hline $\begin{array}{l}\text { Busca por palavras ou frases em } \\
\text { todos os campos }\end{array}$ & & & \\
\hline $\begin{array}{l}\text { Busca por palavras ou frases em } \\
\text { campos determinados }\end{array}$ & & & \\
\hline $\begin{array}{l}\text { Busca por autor/ orientador/ } \\
\text { colaborador/ responsabilidade }\end{array}$ & & & \\
\hline Busca por título & & & \\
\hline Busca por assunto & & & \\
\hline Busca por editora & & & \\
\hline Busca por série & & & \\
\hline Busca por código de barras & & & \\
\hline Busca por ISSN e/ou ISBN & & & \\
\hline Busca por número de sistema & & & \\
\hline Opção de pesquisa simples & & & \\
\hline Opção de pesquisa avançada & \\
\hline $\begin{array}{l}\text { Opção de pesquisa multi-campo } \\
\text { (cruzamento de mais de um campo } \\
\text { ao mesmo tempo) }\end{array}$ & & & \\
\hline $\begin{array}{l}\text { Outros. Especifique. } \\
\text { fumpos }\end{array}$ & & & \\
\hline
\end{tabular}

Fonte: Elaboração própria

A questão 32 constata o que é recomendado para políticas de indexação e o que existe na prática, no que se refere aos programas de treinamento em recuperação da informação oferecidos aos usuários. Questão 32 - Existe um programa de treinamento ao usuário para uso do catálogo em sua instituição? Se sim, como é feito?

Quadro 13 - Avaliação

\begin{tabular}{|l|l|l|l|l|}
\hline & Bibliotecário A & $\begin{array}{c}\text { Bibliotecário } \\
\text { B }\end{array}$ & $\begin{array}{c}\text { Bibliotecário } \\
\text { C }\end{array}$ & $\begin{array}{c}\text { Bibliotecário } \\
\text { D }\end{array}$ \\
\hline Não existe & & & & \\
\hline $\begin{array}{l}\text { Fornecimento e manual de } \\
\text { instruções }\end{array}$ & & & & \\
\hline Treinamento on-line & & & & \\
\hline $\begin{array}{l}\text { Tutorial a página do } \\
\text { sistema }\end{array}$ & & & & \\
\hline $\begin{array}{l}\text { Presencial. Nesse caso, } \\
\text { qual a periodicidade? }\end{array}$ & & & & \\
\hline
\end{tabular}

Fonte: Elaboração própria

A questão 33 objetivou determinar alguns tipos de avaliação existentes, e como essas 
avaliações se dão na prática. Questão 33 - O sistema é avaliado periodicamente através de:

Quadro 14- Treinamento

\begin{tabular}{|l|c|l|l|l|}
\hline & $\begin{array}{c}\text { Bibliotecário } \\
\text { A }\end{array}$ & $\begin{array}{c}\text { Bibliotecário } \\
\text { B }\end{array}$ & $\begin{array}{c}\text { Bibliotecário } \\
\text { C }\end{array}$ & $\begin{array}{c}\text { Bibliotecário } \\
\text { D }\end{array}$ \\
\hline $\begin{array}{l}\text { Questionário distribuído } \\
\text { aos usuários }\end{array}$ & & & & \\
\hline Entrevista com os usuários & & & \\
\hline $\begin{array}{l}\text { Algum mecanismo de } \\
\text { registro de demanda } \\
\text { atendida }\end{array}$ & & & \\
\hline $\begin{array}{l}\text { Algum mecanismo de } \\
\text { registro de demanda } \\
\text { reprimida ou outros }\end{array}$ & & & & \\
\hline Não é feita avaliação & & & & \\
\hline
\end{tabular}

Fonte: Elaboração própria

Questão 34 - Descreva passo-a-passo o processo de indexação que você realiza.

Quadro 15- Processo indexação

\begin{tabular}{|c|c|c|}
\hline Bibliotecário B & Bibliotecário C & Bibliotecário D \\
\hline $\begin{array}{l}\text { Análise do livro para } \\
\text { identificar o assunto; } \\
\text { pesquisa em base de dados; } \\
\text { pesquisa do termo no } \\
\text { Alexandria e na Biblioteca } \\
\text { Nacional para comparar com } \\
\text { os termos utilizados no } \\
\text { Sistema da Biblioteca; } \\
\text { indexação. } \\
\text { Caso não haja o termo no } \\
\text { sistema, é solicitado a } \\
\text { criação, ao setor de } \\
\text { processamento técnico da } \\
\text { BPERJ, enviando a } \\
\text { descrição. }\end{array}$ & $\begin{array}{l}\text { Processo realizado da } \\
\text { linguagem natural para a } \\
\text { controlada em } 5 \text { fases: } \\
\text { 1. Identificação da área de } \\
\text { conhecimento; } \\
\text { 2. Levantamento dos termos } \\
\text { e criação de uma lista de } \\
\text { assuntos em linguagem } \\
\text { natural; } \\
\text { 3. Escolha da linguagem } \\
\text { controlada na base; } \\
\text { 4. Identificação de um } \\
\text { método de relação entre as } \\
\text { linguagens de indexação; } \\
\text { 5. Sistematização do } \\
\text { processo entre linguagens de } \\
\text { indexação para a } \\
\text { compatibilização sintático- } \\
\text { semântica entre os termos. }\end{array}$ & $\begin{array}{l}\text { Identificação do assunto; } \\
\text { pesquisa no Alexandria; se } \\
\text { não houver, pesquisa em } \\
\text { outros catálogos (Biblioteca } \\
\text { Nacional é o mais usado); se } \\
\text { necessário, pedir inclusão do } \\
\text { termo; indexação. }\end{array}$ \\
\hline
\end{tabular}

Fonte: Elaboração própria

Os fatores identificados existentes para o planejamento dentro do sistema de informação foram: identificação da organização à qual está vinculado o sistema de indexação; identificação da clientela a que se destina o sistema e mapeamento dos recursos humanos, materiais e financeiros. 
Os elementos identificados que devem ser considerados ao se elaborar uma política de indexação foram: cobertura de assuntos; seleção e aquisição dos documentos-fonte; processo de indexação (nível de exaustividade, nível de especificidade, escolha da linguagem e capacidade de revocação do sistema); estratégica de busca; tempo de resposta do sistema; forma de saída; avaliação do sistema e capacidade de consulta a esmo.

Dos fatores analisados destacamos: i) a identificação da organização à qual está vinculado o sistema de indexação: este fator é importante, pois conhecer os objetivos e atividades da organização é fundamental para determinar o tipo de serviço a ser implantado. As organizações as quais trabalhamos foram as Bibliotecas Públicas do Estado do Rio de Janeiro; ii) a identificação da clientela a que se destina o sistema: este fator é pré-requisito para o planejamento de um sistema de informação, pois a principal finalidade de um sistema de informação é fornecer ao usuário a informação que precisa. Os usuários dessas bibliotecas em que pesquisamos têm idades variadas e grau de escolaridade variado também; iii) o mapeamento dos recursos humanos, materiais e financeiros: investigamos o número de indexadores, sua formação, quantidade de computadores disponíveis para o processo de indexação, quantidade de computadores disponíveis para a consulta do usuário.

Dos elementos analisados destacamos a: i) Cobertura de assuntos: deve ser tão abrangente quanto a necessidade de informação dos usuários a que a biblioteca se destina. Nas bibliotecas trabalhadas, a cobertura abrange a totalidade dos assuntos dos itens do acervo; ii) Seleção e aquisição dos documentos-fonte: o processamento técnico da BPERJ faz a seleção do que é pertinente para o acervo da BPERJ, da BPN, da Biblioteca Parque de Manguinhos e da Biblioteca Parque da Rocinha. A aquisição é feita por compra e doação; iii) o processo de indexação: a exaustividade prevê de 1 a 5 termos; os termos de indexação são gerais; os termos de indexação são preferencialmente no masculino e no singular; a linguagem documentária usada é a lista de cabeçalhos de assunto, é pré-coordenada; iv) a estratégica de busca: seleção de catálogos, busca por bibliotecas, busca por tipo de material, busca por palavras ou frases em todos os campos, busca por palavras ou frases em campos determinados, busca por autor/ orientador/ colaborador/ responsabilidade, busca por título, busca por assunto, busca por editora, busca por série, busca por código de barras, busca por número de sistema, opção de pesquisa simples, opção de pesquisa avançada, opção de pesquisa multi-campo (cruzamento de mais de um campo ao mesmo tempo; v) o tempo de resposta do sistema: em duas bibliotecas o tempo é de 1 a 10 minutos, e em uma delas o tempo é de mais de 20 minutos; vi) a forma de 
saída: lista de referências em formato resumido (autor e título) na tela do terminal e por email; e vii) a avaliação do sistema: não é feita.

Acerca dos elementos de Foskett (1973):

a) Capacidade de consulta a esmo (browsing): o sistema permite a consulta a esmo.

b) Formação do indexador: um indexador com curso superior completo e dois bibliotecários com especialização;

E, por fim, Rubi (2004), a consulta ao indexador: não é verificado junto aos indexadores quais são as dificuldades eles têm durante o serviço.

\section{Considerações finais}

O levantamento bibliográfico feito para o desenvolvimento do trabalho permitiu constatar que a maioria das pesquisas relacionadas à Política de Indexação foi feita em Bibliotecas Universitárias. Percebe-se que há necessidade de maiores estudos em Política de Indexação para todos os tipos de bibliotecas, pois elas têm diferentes missões, público e necessidades.

Podemos observar que a pesquisa em Política de Indexação no Brasil carece de estudos que possibilitem seu desenvolvimento e, consequentemente, a efetiva contribuição para o profissional em sua atuação na representação da informação em ambientes informacionais, especificamente em bibliotecas públicas.

Embora não fosse objetivo da pesquisa, pôde-se observar a importância e a necessidade da educação continuada para o bibliotecário que atua na função de indexador, visto que os bibliotecários indexadores tiveram dificuldade em responder as perguntas da entrevista por não saber ou lembrar alguns conceitos importantes. Além disso, houve divergência nas respostas relacionadas ao sistema de recuperação da informação e à Política de Indexação. 


\section{Referências}

ALMEIDA JÚNIOR, O. F. Biblioteca pública: avaliação de serviços. Londrina: Eduel, 2000.

ASSOCIAÇÃO BRASILEIRA DE NORMAS TÉCNICAS. NBR 12676: métodos para análise de documentos: determinação de seus assuntos e seleção de termos de indexação: procedimento. Rio de Janeiro, 1992.

RIO DE JANEIRO (Estado). Secretaria de Cultura. [Biblioteca Parque Estadual]. 2017. Disponível em: <http: http://www.cultura.rj.gov.br/apresentacao-espaco/biblioteca-parqueestadual-bpe $>$. Acesso em: 21 mar. 2017.

CARNEIRO, M. V. Diretrizes para uma política de indexação. Revista da Escola de Biblioteconomia da UFMG, Belo Horizonte, v. 14, n. 2, p. 221-241, set. 1985.

CHAUMIER, J. Indexação: conceitos, etapas e instrumentos. Revista Brasileira de Biblioteconomia e Documentação, São Paulo, v. 21, n.1/2, p. 63-79, jan./jun. 1988.

CINTRA, A. M. M. Elementos de linguística para estudos de indexação. Ciência da Informação, Brasília, v.12, n.1, p.5-22, jan./abr. 1983. Disponível em:

<http://revista.ibict.br/index.php/ciinf/article/view/1526/1144>. Acesso em: 30 nov. 2013.

CUNHA, M. B.; CAVALCANTI, C. R. O. Dicionário de Biblioteconomia e Arquivologia. Brasília: Briquet de Lemos, 2008.

FIGUEIREDO, A. M.; SOUZA, S. R. G. Como elaborar projetos, monografias, dissertações e teses: da redação científica à apresentação do texto final. 4.ed. Rio de Janeiro: Lumen Juris, 2011.

FLUSSER, V. Uma biblioteca verdadeiramente pública. Revista da Escola de Biblioteconomia da UFMG, Belo Horizonte, v. 9, n. 2, p. 131-138, 1980.

FOSKETT, A. C. A abordagem temática da informação. São Paulo: Polígono, 1973.

FUNDAÇÃO BIBLIOTECA NACIONAL. Coordenadoria do Sistema Nacional de Bibliotecas Públicas. Biblioteca pública: princípios e diretrizes. Rio de Janeiro, 2000. 160 p. (Documentos técnicos; 6).

GUIMARÃES, J. A. C. A análise documentária no âmbito do tratamento da informação: elementos históricos conceituais. In: RODRIGUES, G. M.; LOPES, I. L. (Org.). Organização e representação do conhecimento na perspectiva da Ciência da Informação. Brasília: Thesaurus, 2003, v. 2, p. 100-117.

HAMPTON, D. R. Administração contemporânea. 3. ed. rev. São Paulo: McGraw-Hill, 1992.

IFLA. UNESCO. Manifesto da IFLA/UNESCO sobre bibliotecas públicas. 1994. Disponível em: <http://archive.ifla.org/VII/s8/unesco/port.htm .>. Acesso em: 5 nov. 2013 
KAHLMEYER-MERTENS, R.S. et al. Como elaborar projetos de pesquisa: linguagem e método. Rio de Janeiro: FGV, 2007.

KOBASHI, N. Y. A elaboração de informações documentárias: em busca de uma metodologia. 1994. 195 f. Tese (Doutorado em Ciências da Comunicação) - Escola de Comunicação e Artes, Universidade de São Paulo, São Paulo, 1994.

LANCASTER, F. W. Indexação e resumos: teoria e prática. 2.ed. Brasília: Briquet de Lemos, 2004.

MAXIMIANO, A. C. A. Introdução à administração. 5.ed. São Paulo: Atlas, 2000.

MENEZES, E. M; CUNHA, M. V. da; HEEMANN, V. M. Glossário de análise documentária. Londrina: ABECIN, 2004. (Teoria e Crítica, 1).

OLIVEIRA, M. (Org.). Ciência da informação e biblioteconomia: novos conteúdos e espaços a atuação. 2. ed. Belo Horizonte: Ed. da UFMG, 2006. 139 p. (Didática).

ROBBINS, S. P. Comportamento organizacional. 11. ed. São Paulo: Pearson/Prentice Hall, 2008.

RUBI, M. P. A política de indexação na perspectiva do conhecimento organizacional, 2004, 116 f. Dissertação (Mestrado em Ciência da Informação) - Universidade Estadual Paulista, Faculdade de Filosofia e Ciências de Marília.

SUAIDEN, E. Biblioteca pública e informação à comunidade. São Paulo: Global, 1995. (Coleção ciência da informação).

VICKERY, B. C. Classificação e indexação nas ciências. Rio de Janeiro: BNG/Brasilart, 1980. 